\title{
Marie Ndiaye, Papa doit manger
}

\author{
Ilaria Vitali
}

\section{(2) OpenEdition}

\section{Journals}

\section{Edizione digitale}

URL: http://journals.openedition.org/studifrancesi/35343

DOI: 10.4000/studifrancesi.35343

ISSN: 2421-5856

\section{Editore}

Rosenberg \& Sellier

\section{Edizione cartacea}

Data di pubblicazione: 1 novembre 2005

Paginazione: 463

ISSN: 0039-2944

\section{Notizia bibliografica digitale}

Ilaria Vitali, «Marie Ndiaye, Papa doit manger», Studi Francesi [Online], 146 (XLIX | II) | 2005, online dal 30 novembre 2015, consultato il 18 avril 2021. URL: http://journals.openedition.org/studifrancesi/35343 ; DOI: https://doi.org/10.4000/studifrancesi.35343

\section{Questo documento è stato generato automaticamente il 18 avril 2021.}

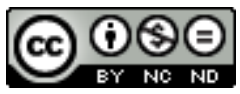

Studi Francesi è distribuita con Licenza Creative Commons Attribuzione - Non commerciale - Non opere derivate 4.0 Internazionale. 


\section{Marie Ndiaye, Papa doit manger}

Ilaria Vitali 


\section{NOTIZIA}

MARIE NDIAYE, Papa doit manger, Paris, Minuit, 2003, pp. 94.

Ecrivain entre-deux, autrice di racconti, romanzi, pièce teatrali, Marie Ndiaye è in grado di trascendere non solo i confini delle sue due culture d'appartenenza, ma anche quelli della stessa letteratura francofona per raggiungere un pubblico internazionale. La sua ultima pièce, Papa doit manger, è entrata a far parte del repertorio della Comédie Française. L'opera mette in scena il ritorno a casa di un padre di famiglia, partito molti anni prima in cerca di fortuna. L'uomo ostenta una presunta ricchezza e una gioventù improbabile, è sicuro di essere accettato, di avere ancora diritti sulla sua famiglia, ed esige di rientrare a far parte della vita di provincia di Courbevoie da cui era fuggito dieci anni prima. Tuttavia, le cose non saranno così semplici. Tutta la pièce sembra essere costruita sull'interrogativo: chi è «Papà»? Un uomo, dalla pelle di un «nero assoluto», che ha fatto fortuna lontano da casa? Un Ulisse che ritorna per essere amato, esigere cure e attenzioni dai suoi cari? La risposta di Ndiaye è semplice e spietata: si tratta solo di un uomo che "deve mangiare», un affamato come tanti, un eroe impostore, un mediocre Otello. Oltre ad avere contenuti sociali di notevole portata, la pièce si carica di un pesante valore simbolico, a tratti autobiografico: come i genitori dell'autrice, «Papà» è nero, «Mamma» è bianca. Tuttavia, Marie Ndiaye non sembra temere cliché e luoghi comuni sul razzismo, e vuole invece servirsene per di-vertirli dall'interno con l'arma dell'umorismo. Sfruttando l'ambiguità irrisolta dei pregiudizi occidentali, l'autrice inserisce in un ambiente «bianco» e stereotipato un Nero, che reclama la sua superiorità e finirà invece per sottostare alle loro leggi. Tragedia contemporanea, la pièce mette in scena l'abbandono, il razzismo, l'odio e l'amore e i difficili rapporti tra Francia e Africa, ponendo l'accento proprio su ciò che spesso l'Occidente tralascia con tanta leggerezza. 